\title{
Structural Changes in Rat Liver Glycogen during Refeeding after Fasting
}

\author{
Yotaro KonISHI and Hidetsugu FUWA* \\ Department of Food and Nutrition, Osaka City University, \\ 3-3-138 Sugimoto, Sumiyoshi-ku, Osaka 558, Japan
}

Received October 27, 1982

\begin{abstract}
Rats starved for $48 \mathrm{hr}$ were refed on a high carbohydrate diet and killed at various intervals ( $3 \sim 24 \mathrm{hr}$ ) in order to examine structural changes in liver glycogen. Glycogen was isolated by the $\mathrm{HgCl}_{2}$ method and thereafter treated with dithizone-chloroform to eliminate $\mathrm{HgCl}_{2}$. The extracted glycogen revealed typical $\alpha$-particles besides $\beta$-particles but the $\mathrm{KOH}$-extracted glycogen showed only $\beta$-particles. The tissue glycogen level began to increase after refeeding and reached a maximum at $18 \mathrm{hr}$. However, the iodine adsorption capacity of the $\mathrm{HgCl}_{2}$-extracted glycogen (but not the $\mathrm{KOH}$-extracted one) increased by $30 \%$ in $6 \mathrm{hr}$-refed rats compared with control rats fed ad libitum, and then decreased to the control level. In the $\mathrm{HgCl}_{2}$-extracted samples, changes in glycogen $S_{20 \text {,w }}$ after refeeding were coincident with the changes in the iodine adsorption capacity and $\beta$-amylolysis limit. On the other hand, these structural changes were not observed in the $\mathrm{KOH}$-extracted samples.

These findings supported that the $\mathrm{HgCl}_{2}$ method is useful for isolating native glycogen and suggested that the liver glycogen structure can be temporarily altered so as to have a high molecular-weight together with high iodine affinity and long outer chains.
\end{abstract}

Chapman et al. observed that glycogen from glycogenesis-activated rat liver could adsorb much more iodine than that in the steady state. ${ }^{1)}$ Schlamowitz reported that absorption spectra of iodine-glycogen complexes and the number of reducing ends of rat liver glycogen reflected the carbohydrate source fed to the rats. ${ }^{2)}$ Their studies suggested that the distribution of glucose moieties in the glycogen molecule could be changed by the nutritional state. However, these workers examined acidor alkali-extracted glycogen for structural analyses. Since either acid or alkali results in the degradation of polysaccharide, ${ }^{3)}$ it is essential to obtain glycogen in the native form from tissues for studying the glycogen structure.

Mordoh et al. isolated a high molecularweight glycogen from rat liver by the $\mathrm{HgCl}_{2}$ method and preliminarily showed that the molecular-weight distribution of the glycogen varied after intubation of a glucose solution to fasting rats. ${ }^{4}$ Bueding and Orrell also reported similar findings in liver fluke, Fasciola he- patica; the high molecular-weight fraction of glycogen disappeared during fasting and reappeared after glucose administration, using cold water instead of $\mathrm{KOH}$ for the isolation of glycogen. ${ }^{5)}$

However, little attention has been paid to the structure of newly-synthesized glycogen and the mechanisms of its formation. Therefore, in order to investigate in detail the structue of newly-synthesized glycogen in vivo, we examined the physical and chemical properties of rat liver glycogen during refeeding after fasting and emphasize the important role of the preparatory procedure for glycogen in this type of study.

\section{MATERIALS AND METHODS}

1) Treatment of rats. Male Sprague-Dawley strain rats $(230 \sim 250 \mathrm{~g})$ were used in these experiments. After rats were fasted for $48 \mathrm{hr}$ to deplete their glycogen store, they were refed ad libitum on a $25 \%$ casein diet from 9:00 hr under a controlled lighting schedule with light from 8:00 to $20: 00 \mathrm{hr}$ at $22^{\circ} \mathrm{C}$, and then killed at various intervals by

* To whom inquiries should be addressed. 
cervical dislocation. The liver was removed promptly and rinsed in cold saline.

\section{2) Isolation of glycogen.}

Method A : Liver $(0.5 \mathrm{~g})$ was digested with $2 \mathrm{ml}$ of $30 \%$ $\mathrm{KOH}$ in a boiling water-bath for 20 min to determine the hepatic glycogen concentration by the method of Hassid and Abraham. ${ }^{6}$

Method B: Liver (5g) was homogenized with $15 \mathrm{ml}$ of chilled $3 \% \mathrm{HgCl}_{2}$ solution ( $\mathrm{pH}$ 5.2). Glycogen was isolated from the $\mathrm{HgCl}_{2}$ soluble fraction by the method of Mordoh et $a .^{4)}$ Usually only one extraction with $\mathrm{HgCl}_{2}$ solution was carried out. The recovery of glycogen by the method was about $62 \%$ of that by the $\mathrm{KOH}$ method, which almost agreed with the previous report. ${ }^{4)}$

Method C: The glycogen sample obtained by method B was shaken with $0.01 \%$ dithizone-chloroform to remove contaminating $\mathrm{HgCl}_{2}$.

3) Determination of sedimentation coefficient of isolated glycogen. Isolated glycogen was dissolved in $0.1 \mathrm{M}$ potassium phosphate buffer ( $\mathrm{pH} 7.2$ ), and insoluble materials were removed by centrifugation $(2000 \mathrm{rpm}, 10 \mathrm{~min})$. The resultant supernatant ( $1 \%$ solution) was transferred to single- and wedge-type cells. Centrifugation was carried out at $7000 \mathrm{rpm}$ in an $\mathrm{RA} 60 \mathrm{H}$ rotor at $28^{\circ} \mathrm{C}$, using a Hitachi-282 analytical ultracentrifuge with a Schlieren optical system.

4) Sucrose density gradient centrifugation. A linear gradient of $10 \sim 40 \%$ sucrose $(15 \mathrm{ml})$ was prepared in a cellulose tube. Glycogen obtained by method C $(1 \%$ solution, $0.5 \mathrm{ml}$ ) was layered over the sucrose solution. The centrifugal force applied was equivalent to $32 \mathrm{~min}$ at $15,000 \mathrm{rpm}$ including acceleration and deceleration times calculated as described by Martin and Ames. ${ }^{7)}$ After centrifugation, each fraction $(1.2 \mathrm{ml})$ was collected and iodine color intensities at $460 \mathrm{~nm}$ of the fractions were measured as described below.

5) Transmission electron microscopy. Isolated glycogen was negatively-stained with $4 \%$ uranyl acetate $(\mathrm{pH}$ 4.1). The specimens were examined with a Hitachi HU-12 microscope at $75 \mathrm{kV}$.

6) $\beta$-Amylolysis. Crystalline $\beta$-amylase from sweet potato (product of Sigma) was purified by the method of Marshall and Whelan. ${ }^{8)}$ Glycogen (1 mg) was dissolved in $0.1 \mathrm{ml}$ of dimethyl sulfoxide (DMSO) at $37^{\circ} \mathrm{C}$ overnight. Then $0.9 \mathrm{ml}$ of $50 \mathrm{~mm}$ acetate buffer $(\mathrm{pH} \mathrm{4.8)}$ containing $40 \mathrm{U}$ of $\beta$-amylase was added. One unit of the enzyme activity is expressed as the amount which liberates $1 \mu \mathrm{mol}$ of maltose per min at $37^{\circ} \mathrm{C}$. Incubation was carried out for $6 \mathrm{hr}$ at $37^{\circ} \mathrm{C}$. Total sugar and reducing power were determined with maltose as a standard.

7) Determination of average chain lengths $(\overline{C L})$. A glycogen sample $(2 \mathrm{mg})$ was incubated with $120 \mathrm{U}$ of Pseudomonas isoamylase (product of Hayashibara Biochemical Laboratories, Inc., Okayama, Japan) in $2 \mathrm{ml}$ of $60 \mathrm{~mm}$ acetate buffer ( $\mathrm{pH} \mathrm{3.5)}$ containing 10\% DMSO for $24 \sim 48 \mathrm{hr}$ at $37^{\circ} \mathrm{C}$. One unit of the enzyme activity is expressed as the amount of enzyme causing an increase in $A_{610 \mathrm{~nm}}$ of $0.1 \mathrm{in} 1 \mathrm{hr}$ as reported previously. ${ }^{9)}$ Average chain lengths were calculated from contents of total and reducing sugars in the reaction mixtures with glucose as a standard.

8) Analytical methods. Total carbohydrates were determined by the phenol-sulfuric acid method, ${ }^{10}$ ) reducing power was determined by either the method of SomogyiNelson ${ }^{11,12)}$ or that of Park-Johnson ${ }^{13)}$ modified by Hizukuri et al. ${ }^{14)}$ Protein determination was carried out by the method of Lowry et al. ${ }^{15)}$ with bovine serum albumin as a standard. The iodine-absorption spectra of glycogen were measured by the method of Krisman. ${ }^{16)}$

\section{RESULTS}

1) Changes in hepatic glycogen levels of rats after fasting and refeeding

Though liver glycogen levels of rats decrease to $0.3 \%$ of wet tissue weight during $48 \mathrm{hr}$ fasting, they begin to increase rapidly after refeeding and reach a maximum $(14 \%$ of wet tissue weight) at $18 \mathrm{hr}$ as shown in Table I. The increases in liver glycogen level were closely correlated with food intake and liver weight till $18 \mathrm{hr}$ after refeeding.

\section{2) Iodine adsorption capacity}

The iodine-absorption spectra of glycogen isolated by methods $\mathrm{A}$ and $\mathrm{C}$ showed an absorption maximum at approximately $460 \mathrm{~nm}$, which was nearly constant among the glycogen samples from fed and refed rats. In the glycogen samples with method $\mathrm{C}$, color intensities at $460 \mathrm{~nm}$ per $\mathrm{mg}$ glycogen of rats $6 \sim 15 \mathrm{hr}$ after refeeding were about $30 \%$ higher than those of rats fed ad libitum as shown in Table I. However, these increased iodine adsorption capacities of glycogen were not observed when glycogen was isolated with $\mathrm{KOH}(\operatorname{method} \mathrm{A})$.

\section{3) Morphology of glycogen particles extrac- ted with $\mathrm{KOH}$ and $\mathrm{HgCl}_{2}$}

Liver glycogen extracted by a mild pro- 
Table I. Changes in Hepatic Glycogen Levels and Iodine Adsorption Capacities of Liver Glycogen of Rats aFter RefeEding

Rats were fed ad libitum or fasted for $48 \mathrm{hr}$. The fasting rats were fed on a $25 \%$ casein diet freely and killed at various times. Liver glycogen was isolated by the $\mathrm{KOH}$ and $\mathrm{HgCl}_{2}$ methods. Contaminating $\mathrm{Hg}$ was removed by treatment with dithizone as described in the text. Glycogen contents and absorbance at $460 \mathrm{~nm}$ of iodineglycogen complexes per mg glycogen were determined as described in MATERIALS AND METHODS.

\begin{tabular}{|c|c|c|c|c|c|c|c|c|}
\hline \multirow{3}{*}{$\begin{array}{c}\text { Hours } \\
\text { after } \\
\text { refeeding }\end{array}$} & \multirow{3}{*}{$\begin{array}{c}\text { Number } \\
\text { of } \\
\text { rats }\end{array}$} & \multirow{3}{*}{$\begin{array}{l}\text { Food } \\
\text { intake } \\
\text { (g) }\end{array}$} & \multirow{3}{*}{$\begin{array}{l}\text { Liver wet } \\
\text { weight } \\
\text { (g) }\end{array}$} & \multirow{3}{*}{$\begin{array}{c}\text { Liver } \\
\text { glycogen } \\
(\mathrm{g} / 100 \mathrm{~g})^{a}\end{array}$} & \multicolumn{4}{|c|}{ Iodine adsorption } \\
\hline & & & & & \multicolumn{2}{|c|}{$\mathrm{HgCl}_{2}$ Method } & \multicolumn{2}{|c|}{$\mathrm{KOH}$ Method } \\
\hline & & & & & $\mathrm{A} / \mathrm{mg}^{b}$ & $(\%)$ & $\mathrm{A} / \mathrm{mg}^{b}$ & $(\%)$ \\
\hline 3 & 3 & 5.2 & 8.67 & 2.48 & 3.15 & 104 & 3.32 & 117 \\
\hline 6 & 2 & 9.1 & 8.34 & 7.11 & 3.87 & 128 & 3.15 & 111 \\
\hline 9 & 4 & 11.5 & 10.54 & 8.56 & 3.67 & 121 & 3.12 & 110 \\
\hline 15 & 2 & 12.6 & 12.61 & 13.28 & 4.00 & 132 & 3.32 & 117 \\
\hline 18 & 2 & 12.6 & 12.55 & 14.35 & 3.51 & 116 & 3.27 & 116 \\
\hline 24 & 3 & 21.6 & 12.71 & 10.57 & 3.54 & 117 & 2.91 & 103 \\
\hline ad libitum & 4 & & 13.76 & 4.65 & 3.03 & 100 & 2.83 & 100 \\
\hline
\end{tabular}

a Standard error for each value was less than $13.2 \%$ of the mean.

b Standard error for each value was less than $9.2 \%$ of the mean.
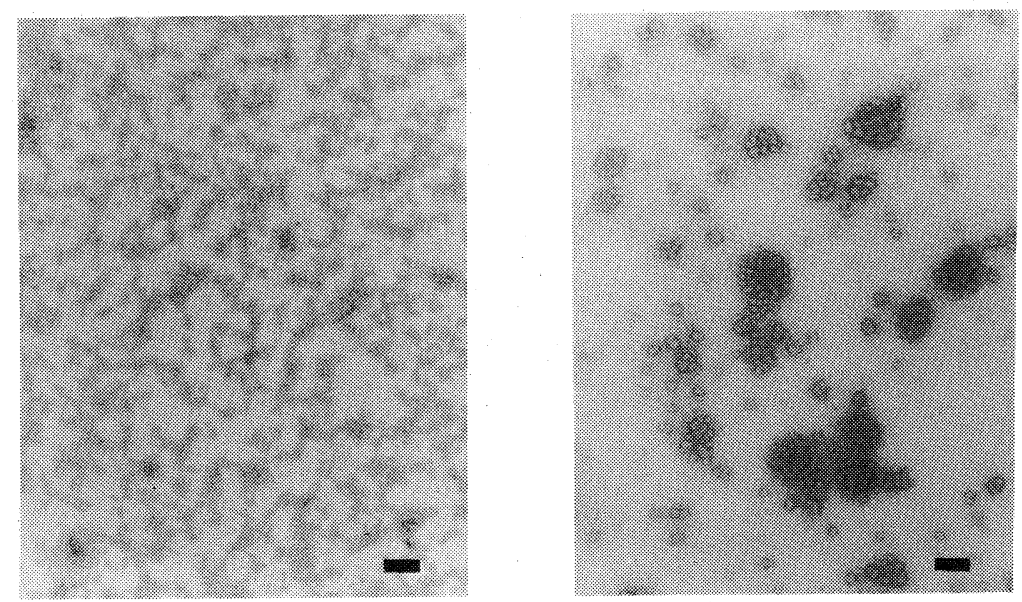

FIG. 1. Electron Micrographs of $\mathrm{KOH}$-Extracted (left) and $\mathrm{HgCl}_{2}$-Extracted (right) Glycogen $(\times 29,000)$.

Bars indicate $200 \mathrm{~nm}$.

cedure appears as large particles. Acid or alkali has been used to isolate tissue glycogen quantitatively but these solvents decrease the size and molecular weight of glycogen measured by electron microscopy ${ }^{17)}$ and ultracentrifugation analysis ${ }^{3,18)}$ Therefore we compared the size of glycogen extracted with alkali and $\mathrm{HgCl}_{2}$ by electron microscopy. As shown in Fig. 1, the $\mathrm{KOH}$-extracted glycogen revealed single spheres of about $35 \mathrm{~nm}$ in diam- eter ( $\beta$-particles). On the other hand, amorphous and various sizes of particles ( $60 \sim 200 \mathrm{~nm}$ in diameter, $\alpha$-particles) besides $\beta$-particles were identified in the $\mathrm{HgCl}_{2}$ extracted sample and were not affected apparently by the dithizone treatment (data not shown).

\section{4) Sedimentation coefficient of glycogen} To determine the physical properties of gly- 
cogen isolated by the present procedures, the sedimentation coefficient of glycogen was determined in Svedberg units. First, for glycogen from the same rat fed ad libitum, the effect of the isolation method on $S_{20 \text {, w }}$ was examined. $S_{20 \text {,w }}$ of the KOH-extracted sample was calculated to be $113 \mathrm{~S}$ (Table II), which agreed with

Table II. Sedimentation Coefficients of RAT LIVER GLYCOGEN

\begin{tabular}{cccc}
\hline $\begin{array}{c}\text { Conditions } \\
\text { of rats }\end{array}$ & $\begin{array}{c}\text { Method of } \\
\text { isolation }^{a}\end{array}$ & $S_{20, \mathrm{w}}$ & $(\%)$ \\
\hline ad libitum & $\mathrm{A}$ & $113^{b}$ & \\
ad libitum & $\mathrm{B}$ & $198^{b}$ & \\
ad libitum & $\mathrm{C}$ & $152^{b} 165$ & $(100)$ \\
3-hr refed & $\mathrm{C}$ & 165176 & $(108)$ \\
6-hr refed & $\mathrm{C}$ & 218196 & $(130)$ \\
9-hr refed & $\mathrm{C}$ & 189188 & $(119)$ \\
\hline
\end{tabular}

a A, $\mathrm{KOH} ; \mathrm{B}, \mathrm{HgCl}_{2} ; \mathrm{C}, \mathrm{HgCl}_{2}$ /dithizone.

$b$ Glycogen from the same rat liver.

$S_{20 \text {,w }}$ of glycogen, which corresponded to the main peak shown in Fig. 2, was determined by analytical ultracentrifugation with a Schlieren optical system. the value reported previously. ${ }^{19}$ ) The $\mathrm{HgCl}_{2}$ extracted one was $198 \mathrm{~S}$ and decreased to $156 \mathrm{~S}$ on treatment with dithizone. The decrease in $S_{20, w}$ on the treatment may be due to elimination of protein adsorbed on glycogen granules. In fact, the protein concentration in the prepared glycogen fell from an average of $1.23 \%$ to $0.31 \%$ with the treatment.

Figure 2 shows ultracentrifugal patterns of glycogen extracted by method C. A small and distinct peak (indicated by arrow in Fig. 2), which precedes the main peak, was detected in samples from refed rats but not in those fed $a d$ libitum, suggesting that glycogen of the refed rats exhibits heterogeneous and wide molecular-weight distributions.

Figure 3 shows the fractionation of glycogen (method C) by sucrose gradient centrifugation. Heavy fractions (fraction Nos. $6 \sim 12$ ) are observed in the samples from $6 \mathrm{hr}-$ and $9 \mathrm{hr}$-refed rats but have disappeared in the control glycogen. The heavy fraction may correspond to glycogen of higher $S_{20, w}$, seen as the small
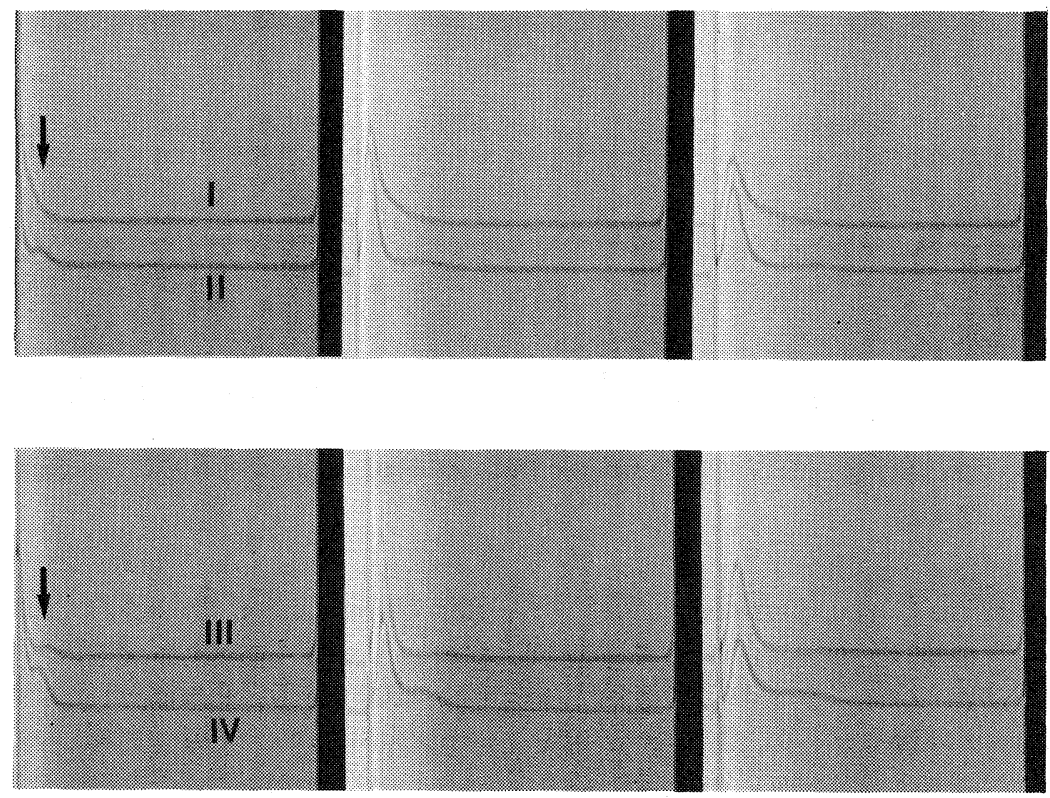

$6 \mathrm{~min}$

$12 \mathrm{~min}$

$18 \mathrm{~min}$

FIG. 2. Sedimentation Patterns of Liver Glycogen (extracted by method C) of Rats Fed ad libitum (I), 6-hr Refed (II), 9-hr Refed (III), and 3-hr Refed (IV).

Photographs were taken at 6 min intervals. 


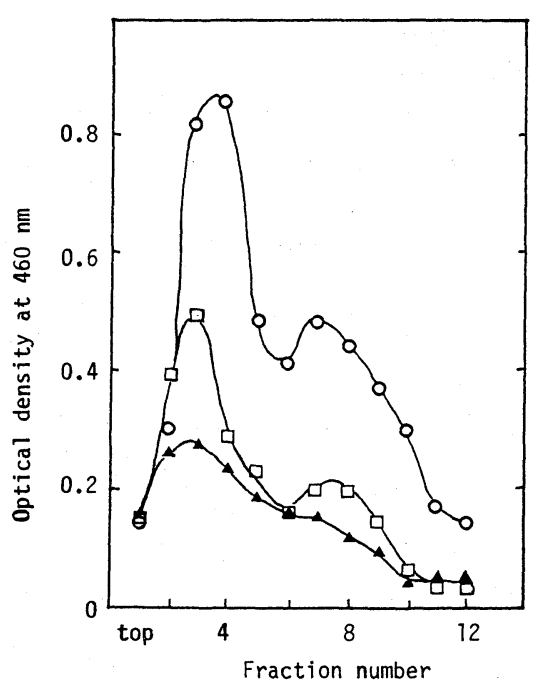

FIG. 3. Fractionation of Glycogen by Sucrose Density Gradient Centrifugation.

Glycogen ( $0.5 \mathrm{mg}$, by method $\mathrm{C}$ ) was fractionated on a $10 \sim 40 \%$ linear sucrose gradient and absorbance at $460 \mathrm{~nm}$ of iodine-glycogen complexes of each fraction was measured as described in the text. ( $\boldsymbol{\Delta})$, rats fed ad libitum; (O), 6-hr refed; ( $\square$ ), 9-hr refed.

peak in Fig. 2.

\section{5) $\beta$-Amylolysis}

Next we determined $\beta$-amylolysis limits of glycogen which showed different physical characteristics as observed above. As shown in Fig. $4, \beta$-amylolysis limits $(\%)$ of the $\mathrm{KOH}-$ extracted glycogen from both fed and refed rats are similar at about $40 \%$ as reported previously. ${ }^{20)}$ On the other hand, the $\mathrm{HgCl}_{2}$ extracted one showed lower $\beta$-amylolysis limits than those of the $\mathrm{KOH}$-extracted samples but were dependent on the duration of refeeding. When these samples were treated with hot alkali $\left(100^{\circ} \mathrm{C}, 10 \mathrm{~min}\right)$, the $\beta$-amylolysis limit increased to return to that seen in the original alkali-extracted samples (see Table III and Fig. 4).

6) Average chain lengths $(\overline{C L})$ of debranched glycogen

To examine whether the glycogen character-

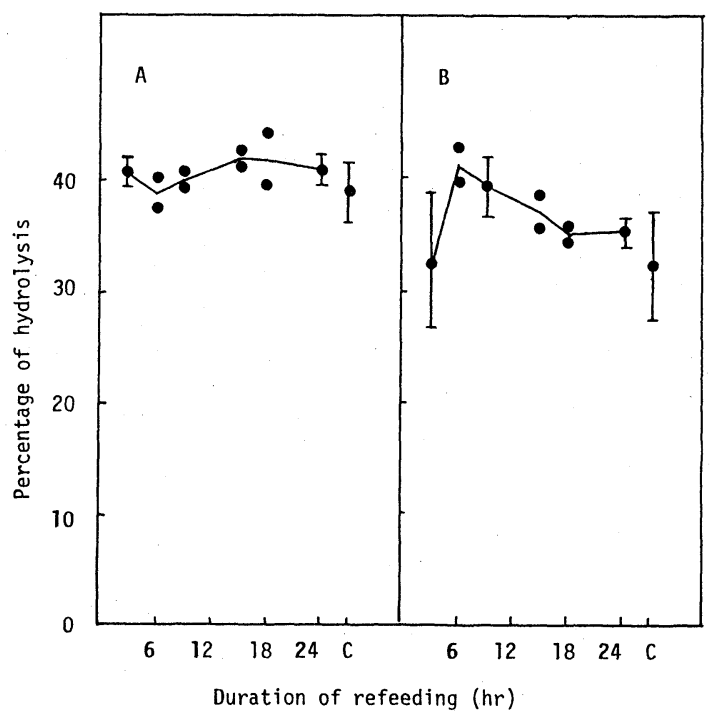

FIG. 4. $\beta$-Amylolysis Limit ( $\%$ ) of Liver Glycogen from Rats after Refeeding and from Control (C) Rats Fed ad libitum.

Glycogen was isolated by the $\mathrm{KOH}$ method (A) and by the $\mathrm{HgCl}_{2}$ method/dithizone treatment (B). Symbols and bars are average $\pm \mathrm{SE}$ of $3 \sim 4$ rats.

TABLE III. $\beta$-AMYLOLYSIS Limits ( $\%$ ) OF THE $\mathrm{HgCl}_{2}$-EXTRACTED GLyCOGEN WITH and without Alkali Treatment

\begin{tabular}{lcc}
\hline & Non-treatment & Alkali-treatment $^{a}$ \\
\hline \multirow{2}{*}{ ad libitum } & 33 & 38 \\
\multirow{3}{*}{ 9-hr refed } & 33 & 37 \\
& 36 & 45 \\
& 37 & 45 \\
\hline
\end{tabular}

a $1 \mathrm{~m} \mathrm{KOH}, 100^{\circ} \mathrm{C}$ for $10 \mathrm{~min}$.

istics (higher in $S_{20, w}$, iodine-adsorption capacity, and $\beta$-amylolysis limit compared with those of the control) are related with the distribution of $\alpha-1,4$ chains of glycogen, glycogen obtained by method $\mathrm{C}$ was debranched by isoamylase. As shown in Fig. 5, $\overline{C L}$ of debranched glycogen from $9 \sim 15 \mathrm{hr}$ refed rats were about 13 , longer by 1.5 glucose units than that of the control. Similar results were obtained with samples extracted by method B and by the TCA-method.* The products after debranching by isoamylase were sepa-

* We previously obtained similar results with the periodate oxidation method for the determination of $\overline{C L}$. (H. Fuwa, unpublished data.) 


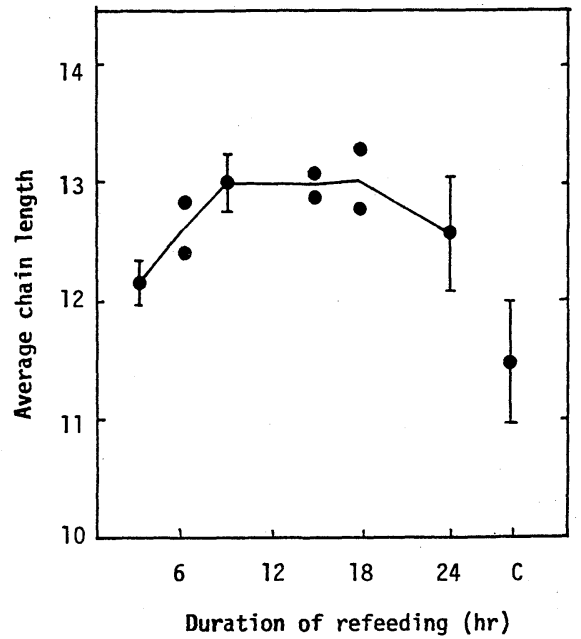

FIG. 5. Average Chain Lengths $(\overline{C L})$ of Liver Glycogen from Refed and Control (C) Rats Fed ad libitum.

Glycogen samples (method C) were debranched by isoamylase to determine $\overline{C L}$ as described in the text. Symbols and bars are average $\pm \mathrm{SE}$ of $3 \sim 4$ rats.

rated by Sephadex G-75 column chromatography, giving one peak (data not shown) as reported before. ${ }^{21)}$

\section{DISCUSSION}

Glycogen is generally assumed to be synthesized by the cooperative action of glycogen synthase (EC 2.4.1.11) and branching enzyme (EC 2.4.1.18), and is catabolized mainly by phosphorylase (EC 2.4.1.1), debranching enzymes (EC 3.2.1.33 and EC 2.4.1.25), and lysosomal $\alpha$-glucosidase (EC 3.2.1.3). The glycogen structure is considered to be dependent essentially on glycogen synthesizing enzymes. For example, the structure of glycogen from tissues of patients with several distinct glycogen storage diseases has been extensively studied. 22,23) Among them glycogen from a patient with Type IV glycogenosis, in which branching enzyme was deficient, had an abnormal structure like amylopectin. ${ }^{24,25)}$ In other types, the structure of glycogen was almost normal. ${ }^{22)}$

In higher plants [especially in maize mutants having a starch modifying gene, amyloseextender, dull, and sugary-126 28) $]$, the exis- tence of isozymes of branching enzyme has been demonstrated which affect the fine structure of amylopectin. ${ }^{29 ~ 31)}$ Though branching enzymes in animals and plants are considered to have an essential role as to structural characteristics of glycogen and starch, the mechanism of regulation of the enzyme in animal tissue is still unknown even though two forms (free and RNA-bound) of rat liver branching enzyme have been recently identified. ${ }^{32)}$

In the present study, we characterized the glycogen structure of rat liver which was changed transiently by a nutritional effect. First, with the $\mathrm{HgCl}_{2}$-method for isolation of glycogen, we confirmed that the newly-synthesized glycogen during refeeding after fasting could adsorb much more iodine as observed by Chapman et al. ${ }^{1)}$ However, glycogen with the $\mathrm{KOH}$ method failed to show the phenomenon, which differed from the results of Chapman et al. ${ }^{1)}$ This discrepancy may be due to the differences in experimental conditions used including the assay for iodine absorption spectra. Second, glycogen having a high iodine adsorption capacity showed a relatively higher $S_{20, \mathrm{w}}$ and $\beta$-amylolysis limit. In general, $S_{20, w}$ determined by us was rather smaller than that reported previous1y. ${ }^{4)}$ Mordoh et al. did not examine the effect of dithizone treatment, and failed to observe the distinct correlation between $S_{20 \text {,w }}$ and liver glycogen content. ${ }^{4)}$ Our results clearly show that $S_{20 \text {,w }}$ is correlated with the duration of refeeding (see Table II). Elimination of $\mathrm{HgCl}_{2}$ by dithizone treatment may result in minimization of deviation of an individual value compared with that of nontreated samples.

$\beta$-Amylolysis limits of the $\mathrm{HgCl}_{2}$-extracted glycogen were estimated to be characteristic of the structure of glycogen obtained at different stages of refeeding. Increased $\beta$-amylolysis limits of glycogen from $6 \sim 9$-hr refed rats suggested the possibilities that these glycogens have longer outer chains and/or a higher degree of branching in their exterior chains. But the latter possibility is not acceptable because the iodine color intensity per unit weight of 
glycogen varied inversely to the degree of branching. ${ }^{2)}$ We rather think that the outer chain lengths of these glycogens are relatively longer and thus capable of helix formation, resulting in the observed high iodine adsorption capacity. As described before, when the $\mathrm{HgCl}_{2}$-extracted glycogen was treated with hot alkali, the $\beta$-amylolysis limit of the sample increased (Table III). The rate of the increase was higher in 9-hr refed rats than in the control ones. This suggests that the outer chains of glycogen from the refed rats were much more folded in the glycogen molecules since these glycogens are of high molecular-weight and are composed of $\alpha$-particles as shown by electron microscopy.

Drochmans observed that filament-like glucoside linkage chains sprouted from $\beta$ particles when $\beta$-particles were incubated with phosphorylase and G-1-P. ${ }^{19}$ ) It is therefore now assumed that the glycogen $\alpha$-particle is an associate of some $\beta$-particles, linked in series by an $\alpha-1,4$ linear chain which is $20 \sim 40$ glucose residues, as calculated by electron microscopy. ${ }^{33,34)}$

We tried to separate the $20 \sim 40$ glucose unit chain by Sephadex G-75 column chromatography from the products after debranching of glycogen $(60 \mathrm{mg})$, but could not detect peaks corresponding to the chains on measuring $\overline{D P}$ and $\lambda_{\max }$ of iodine absorption spectra. The reason for this is that the chains have less glucose residues compared with $\beta$-particle glycogen $\left(55,000\right.$ glucose residues). ${ }^{4,35)}$ Therefore, the small difference in $\overline{C L}$ of debranched glycogen from refed and control rats (Fig. 5) may be reflected in $\overline{C L}$ of $\beta$-particle glycogen themselves.

It has been shown that animal tissue glycogen is metabolically inhomogeneous with respect to molecular weight. ${ }^{36,37)}$ Namely, high molecular-weight glycogen in the liver may be preferentially attacked by glycogen catabolizing enzymes, ${ }^{38)}$ and furthermore labeled glucose could be less incorporated into high molecular-weight glycogen than into a low molecular-weight one. ${ }^{39)}$ Thus it is likely that the glycogen level in tissues is controlled by increased susceptibility of the newlysynthesized glycogen, which is of high molecular-weight, to catabolizing enzymes and, as a result, transient changes in the glycogen structure take place. However, further work is needed on the details of the phenomenon.

Acknowledgments. We are grateful to Dr. K. Masuda, Mr. M. Fujimoto and Mr. T. Kashiyama of Tokushima University for their skillful assistance in electron microscopy. We also wish to thank Mr. R. Kunai of Tokushima University, General Laboratory, for carrying out the sedimentation measurements, and also Dr. K. Iwaki in our laboratory for her technical assistance and advice.

\section{REFERENCES}

1) D. D. Chapman, J. M. Fells and I. L. Chaikoff, Experientia, 11, 283 (1955).

2) M. Schlamowitz, J. Biol. Chem., 188, 145 (1951); 190, 519 (1951).

3) M. R. Stetten and H. M. Katzen, J. Am. Chem. Soc., 83, 2912 (1961).

4) J. Mordoh, C. R. Krisman and L. F. Leloir, Arch. Biochem. Biophys., 113, 265 (1967).

5) E. Bueding and S. A. Orrell, Jr., J. Biol. Chem., 236, 2854 (1961).

6) W. Z. Hassid and S. Abraham, "Methods in Enzymology," Vol. III, ed. by S. P. Colowick and N. O. Kaplan, Academic Press Inc., New York, N. Y., 1957, p. 37.

7) R. G. Martin and B. N. Ames, J. Biol. Chem., 236, 1372 (1961).

8) J. J. Marshall and W. J. Whelan, Anal. Biochem., 52, 642 (1973).

9) K. Yokobayashi, A. Misaki and T. Harada, Biochim. Biophys. Acta, 237, 422 (1971).

10) M. Dubois, K. A. Gilles, J. K. Hamilton, P. A. Roberts and F. Smith, Anal. Chem., 28, 350 (1966).

11) M. Somogyi, J. Biol. Chem., 195, 19 (1952).

12) N. Nelson, J. Biol. Chem., 153, 375 (1944).

13) J. Park and M. J. Johnson, J. Biol. Chem., 181, 149 (1949).

14) S. Hizukuri, Y. Takeda and M. Yasuda, Carbohydr. Res., 94, 205 (1981).

15) O. H. Lowry, N. J. Rosebrough, A. L. Farr and R. J. Randall, J. Biol. Chem., 193, 265 (1951).

16) C. R. Krisman, Anal. Biochem., 4, 17 (1962).

17) P. Drochmans, J. Ultrastruct. Res., 6, 141 (1962).

18) S. A. Orrell and E. Bueding, J. Biol. Chem., 239, 4021 (1964).

19) P. Drochmans, Ann. N. Y. Acad. Sci., 210, 46 (1973).

20) A. J. Parodi, C. R. Krisman, L. F. Leloir and J. 
Mordoh, Arch. Biochem. Biophys., 121, 769 (1967).

21) H. Akai, K. Yokobayashi, A. Misaki and T. Harada, Biochim. Biophys. Acta, 237, 422 (1971).

22) B. Illingworth and G. T. Cori, J. Biol. Chem., 199, 653 (1952).

23) O. Kjølberg and D. J. Manners, J. Chem. Soc., 4596 (1962).

24) L. W. J. Hollman, J. A. Van der Haar and G. A. M. de Vaan, Lab. Invest., 15, 357 (1966).

25) C. Mercier and W. J. Whelan, Eur. J. Biochem., 16, 579 (1970).

26) C. D. Boyer and J. Preiss, Carbohydr. Res., 61, 321 (1978).

27) C. D. Boyer and J. Preiss, Plant Physiol., 67, 1141 (1981).

28) C. D. Boyer, E. K. G. Simpson and P. A. Damewood, Stärke, 34, 81 (1982).

29) Y. Ikawa, D. V. Glover, Y. Sugimoto and H. Fuwa, Carbohydr. Res., 61, 211 (1978).
30) Y. Ikawa, D. V. Glover, Y. Sugimoto and H. Fuwa, Stärke, 33, 9 (1981).

31) J. Y. Yeh, D. L. Garwood and J. C. Shannon, Stärke, 33, 222 (1981).

32) K. Satoh and K. Sato, J. Biochem., 91, 1129 (1982).

33) J. Mordoh, L. F. Leloir and C. R. Krisman, Proc. Natl. Acad. Sci. U.S.A., 53, 86 (1956).

34) M. Nakamura, Denpun Kagaku, 21, 81 (1974).

35) E. Goldsmith, S. Sprang and R. Fletterick, J. Mol. Biol., 156, 411 (1982).

36) M. R. Stetten, H. M. Katzen and D. Stetten, Jr., J. Biol. Chem., 222, 587 (1956).

37) R. Geddes, Int. J. Biochem., 2, 657 (1971).

38) R. Geddes, Carbohydr. Res., 7, 493 (1968).

39) S. A. Orrell, Jr., E. Bueding and M. Reissig, "Ciba Foundation Symposium on Control of Glycogen Metabolism," ed. by W. J. Whelan and M. P. Cameron, Churchill, London, 1964, p. 29. 